\title{
Public good messaging motivates the wealthy to reduce water consumption
}

\author{
Gordon Kraft-Toddd,", Rachit Dubey ${ }^{\mathrm{b}, *}$, Erez Yoelic, David Rand ${ }^{\mathrm{c}}$, Syon P. Bhanot ${ }^{\mathrm{d}}$ \\ ${ }^{\mathrm{a}}$ Department of Psychology and Neuroscience, Boston College, Chestnut Hill MA, 02467 \\ ${ }^{b}$ Department of Computer Science, Princeton University, Princeton NJ, 08540 \\ ${ }^{c}$ Massachusetts Institute of Technology Sloan School of Management, Cambridge MA, 02142 \\ ${ }^{\mathrm{d} D e p a r t m e n t ~ o f ~ E c o n o m i c s, ~ S w a r t h m o r e ~ C o l l e g e, ~ S w a r t h m o r e ~ P A, ~} 19081$ \\ * denotes equal contribution
}

Word Count: 1,728

Author Note

Gordon T. Kraft-Todd: https://orcid.org/0000-0003-1220-9269

Rachit Dubey: https://orcid.org/0000-0001-8216-1999

Erez Yoeli: https://orcid.org/0000-0002-8459-017X

David Rand: https://orcid.org/0000-0001-8975-2783

Syon Bhanot: https://orcid.org/0000-0003-2765-0532

We have no known conflict of interest to disclose.

Correspondence concerning this article should be addressed to: Syon Bhanot, Department of Economics, Swarthmore College, 500 College Ave, Swarthmore PA, 19081; phone: (848) 391-8736; fax: email: sbhanot1@ swarthmore.edu. 


\begin{abstract}
:
Motivating the wealthy to engage in sustainable behaviors is both crucial and challenging; they consume vastly more resources per capita than less wealthy individuals, and they are relatively unresponsive to economic incentives (e.g., taxes). To test whether appeals advocating sustainable behavior may be more effective for the wealthy when framed in terms of the prosocial benefit, we conduct a field experiment to reduce residential water use among 10,500 high-income households in the state of Connecticut. In a 9-month campaign, we find that messages emphasizing the "Public Good" (e.g., to the environment) are more effective in motivating the wealthy to conserve water than messages emphasizing the "Private Benefit" (i.e., financial savings) as well as a control (no messaging). We conceptually replicate these results using two field experiments (one preregistered) that reached 59,882 Facebook users from high-income households in New England, showing significantly greater engagement with prosocial compared to self-interested framed posts.
\end{abstract}

Keywords: Water Conservation | Public Goods | Framing | Wealth | Cooperation | Prosocial Motivation | Sustainability

\title{
Statement of Relevance:
}

The wealthy have an outsized impact on many real-world public goods problems, consuming vastly more resources per capita than less wealthy individuals. This creates a challenge for promoting sustainability, because the wealthy are relatively unresponsive to economic incentives like fees, fines and taxes. We therefore test whether resource conservation messaging is more effective when the benefits of doing so are framed in prosocial rather than financial terms. In a field experiment of a 9-month residential water use reduction messaging campaign among 10,500 relatively high-income households in the state of Connecticut, we show that prosocial framing significantly reduces water use. We conceptually replicate this result in two field experiments that reached 59,882 high-income Facebook users in New England, showing that prosocial framing results in significantly greater engagement. Our findings emphasize the promise of non-material "social incentives" for encouraging sustainability, among the wealthy. 


\section{Introduction}

The wealthy consume a disproportionate share of many key resources, and thus have an outsized impact on issues of environmental sustainability, such as resource depletion, pollution, and climate change (Wiedmann et al., 2020). For example, the top $10 \%$ of income earners contribute $48 \%$ of all $\mathrm{CO}_{2}$ emissions (Chakravarty et al., 2009). The United States is a particularly important testing ground for reducing consumption by the wealthy, as it contains by far the highest proportion of extremely wealthy individuals, including $39 \%$ of the top $1 \%$ of global wealth holders (Shorrocks et al., 2020). Additionally, U.S. households earning $\$ 140,000$ or more use $21.4 \%$ more energy per capita than the average U.S. household (U.S. Energy Information Administration, 2015) and a $10 \%$ increase in household income is associated with a $20 \%$ increase in water consumption (Harlan et al., 2009). Given the increasing urgency of confronting the climate crisis (IPCC, 2021), efforts to encourage sustainable behaviors would thus benefit greatly from changes in the behavior of this relatively small group of individuals.

Motivating wealthy Americans to engage in climate action faces obstacles, however. Traditional economic (i.e., material) incentives such as rate hikes, taxes, and subsidies are unlikely to be effective for people who are relatively wealthy. Because of their wealth, the rich tend to be relatively insensitive to price, for example in the context of energy (Reiss \& White, 2005), water (Grafton et al., 2011), gasoline (West, 2004), and airline flights (Brons et al., 2002). There is also some evidence that higher socioeconomic status (SES) individuals tend to be less prosocial (Piff et al., 2010) - and more antisocial (Piff et al., 2012) — than lower SES individuals in some situations (although see work demonstrating situational moderation and/or failure to replicate this effect; e.g. Dubois et al., 2015; Korndörfer et al., 2015)

Residential water use is a particularly good example of a context in which material incentives are unlikely to drive behavior change among the wealthy. Higher income earners use more water, demand for water is relatively insensitive to price regardless of income (Sebri, 2014), and this price insensitivity increases with wealth (Worthington \& Hoffman, 2008).

While appeals to self-interest may not be effective in motivating the wealthy to reduce their water consumption, prosocial appeals may be more promising. For example, research on cooperation using economic games finds that framing public goods interactions in language emphasizing terms like "community" and "cooperation" leads to greater prosocial behavior (Engel \& Rand, 2014; Liberman et al., 2004; Tenbrunsel \& Messick, 1999). Similarly, framing private health behaviors in terms of their impact on others can increase participants' behavioral intentions (e.g. for COVID-prevention behaviors; Jordan et al., 2020), as well as actual behavior (e.g. for hand-washing among medical professionals; Grant \& Hofmann, 2011). Most relevant to the current investigation, research consistently shows that appeals to the greater good are more effective than appeals to self-interest in motivating pro-environmental behavioral intentions (e.g., willingness to enroll in residential energy-saving programs; Schwartz et al., 2015), as well as proenvironmental behaviors (e.g., for tire pressure checks; Bolderdijk et al., 2013). Further, the relative efficacy of these message frames extends to spill-over effects as well; for example, electricity use reduction messages framed in terms of environmental impact increase behavioral intentions for other climate action whereas messages framed in terms of monetary saving do not (Steinhorst et al., 2015), and participants were more likely to recycle a sheet with study instructions after completing a quiz in which carpooling was discussed in terms of its environmental compared to financial impact (Evans et al., 2013). We are unaware, however, of any work examining whether prosocial appeals are more effective than self-interested appeals for motivating the wealthy to engage in climate action or resource use reduction. 
Thus, in this paper, we seek to determine if messages targeting the rich and encouraging water use reduction will be more effective if they are framed as public goods contributions rather than (private) cost-saving measures.

\section{Open Practices Statement}

The data for Experiment 1 are not publicly accessible due to privacy concerns and data for Experiment 2 are reported in the manuscript (see Table 1). Researchers interested in additional analyses are encouraged to contact the corresponding author. Materials for Experiment 1 are publicly accessible in the SOM. Materials for Experiment 2 are reported in the manuscript (see Figure 4a; the only variations involved state names based on users' location and formatting based on users' platform). There is not a preregistration for Experiments 1 and $2 \mathrm{a}$. There is a preregistration for Experiment 2b, available here: https://osf.io/yts2q.

\section{Experiment 1}

In Experiment 1, we conducted a large-scale field experiment $(N=10,500)$ in partnership with WaterSmart Software and a public utility company in Connecticut. We randomly assigned households to one of three groups: 1) a Control group that received no communications; 2) a "Public Good" treatment; and 3) a "Private Benefits" treatment. Both treatment conditions received five Home Water Reports (HWRs) over nine months by mail or email from WaterSmart, with messages that emphasized either the benefits to the community from conservation (the "Public Good" treatment) or the financial benefits of water conservation (the "Private Benefits" treatment). We hypothesized that, compared to the Control group, wealthy households receiving the "Public Goods" treatment would reduce their water use to a greater extent than those receiving the "Private Benefits" treatment.

\section{Methods}

Experiment 1 involved 10,500 households from wealthy suburban areas in Connecticut; based on estimated real estate values, our sample is more than twice as wealthy as the average American household (see Fig 1a and SI Section 1). WaterSmart Software (a residential water use software company), in cooperation with local utility companies, provided us with data on household water use in this sample, which had been pre-identified by the utility as a target community for water reduction messaging. We randomly assigned households to one of three groups: 1) a Control group $(N=2,625) ; 2)$ a "Public Good" treatment $(N=3,908)$; and 3) a "Private Benefits" treatment $(N=3,967)$. We excluded 49 households that had at least one large outlier (over 10,000 gallons of water use per day), based on advice from our research partners that such observations are likely the result of leaks rather than purposeful consumption decisions. ${ }^{1}$ Also, for 299 households, we only obtained either pre- or post-treatment readings (but not both) and thus we did not include these households in our analysis. After these exclusions, our final sample was $N=10,152$ residences (Control=2,534; "Public Good"=3,776; "Private Benefits"=3,842).

\footnotetext{
${ }^{1}$ We also changed the value of two household-level control variables to missing due to the implausibility of the values, which may have been a result of transcription error.
} 

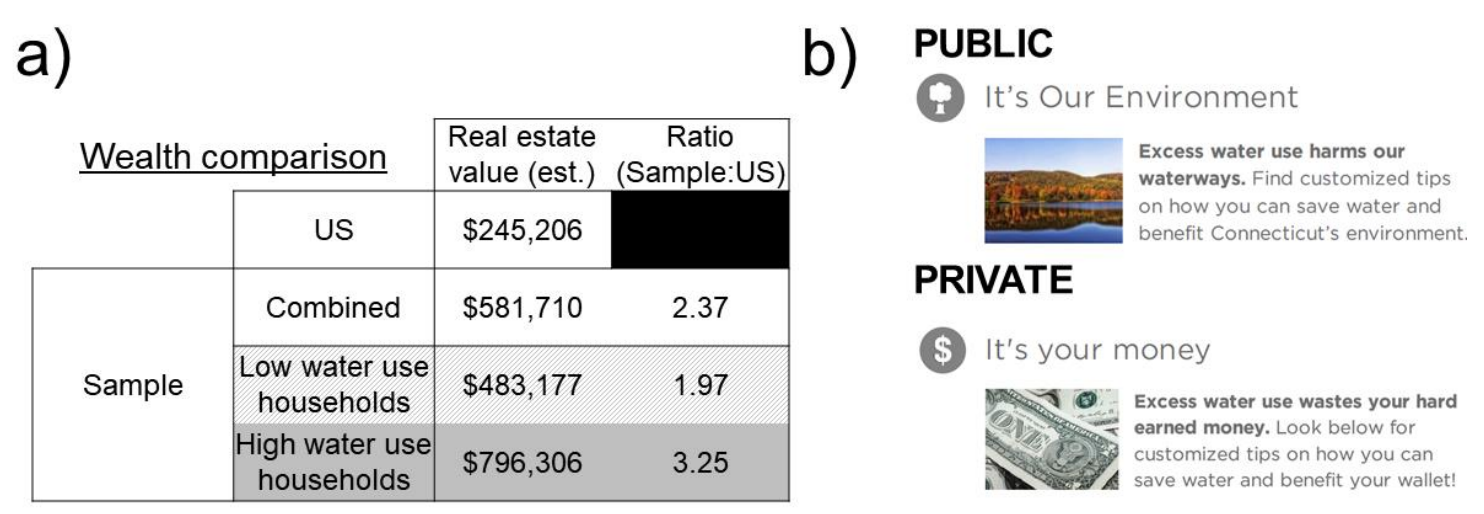

Figure 1. Information about our sample and treatments. Shown are: (a) Comparison of estimated real estate values in our sample (including among low and high prior water use households) with statistics on US households. (b) Example text from one iteration of our "Public Good" and "Private Benefit" treatment conditions included in HWR mailers (see SI Section 3 for complete experimental materials).

Households in both treatment conditions received six Home Water Reports (HWRs), sent every two months by mail or email from WaterSmart (see SI Section 3 for complete experimental materials). These included information on the water use of those homes and their neighbors, tips on conservation, and other information. Our intervention involved randomizing the messaging included in a prominent content box on the upper right portion of the last five of the bimonthly HWRs (the first HWR was the same across treatment groups and contained neither of the treatment messages). The Public Good treatment received five messages that emphasized the benefits to the community from conservation (the environmental benefits, the importance of protecting resources, etc.). The Private Benefit treatment received five messages that emphasized the financial benefits of water conservation (the money saved for the household when reducing water use).

We employ the same regression technique used in prior work with similar datasets (e.g. Bhanot, 2017; List et al., 2017), which examines post-treatment data and includes controls for within-household water use (i.e. water use in the same calendar month of the previous year) and seasonal trends in water use (using month dummies). We note that because our analyses were not preregistered, we attempt to limit researcher degrees of freedom by presenting analyses without control variables in the main text. Still, our results are robust to including all available householdlevel data (e.g. house size, irrigable area, year of construction) as controls (see SI Section 2). Data analysis was completed using STATA 16.

\section{Results}

We compared household water use across the three conditions for each month in the experiment. We begin by comparing overall water use across conditions. Figure 2 shows the average treatment effects (in gallons per day) of the two versions of treatment messaging, relative to the control group not receiving any messages. The Private Benefit treatment had a small and non-significant effect on water use relative to control (coeff=-3.77, 95\% CI[-13.14, 5.60], $t=-.79$, $p=.431)$. The Public Good treatment caused a 11.22 gallon per day reduction in water use relative to control (95\% CI[-20.61, -1.84], $t=-2.34, p=.019)$. Further, the Public Good treatment caused a marginally larger reduction in water use compared to the Private Benefit treatment $(F(1,10149)=3.27, p=.071)$. 


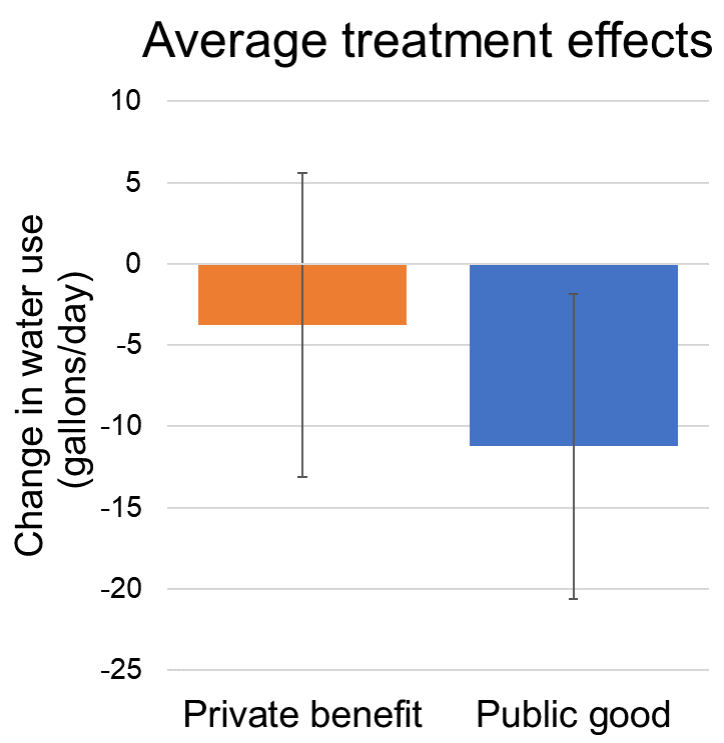

Figure 2. Public Good messaging reduces water use more than Private Benefit messaging. Shown are average treatment effects on gallons per day relative to control of the Private Benefit (orange) and Public Good (blue) messaging treatments. Treatment effects calculated from regression models without controls. Error bars represent $95 \%$ confidence intervals.

To the extent that they are effective, the messaging treatments might be expected to have a larger impact on households that are inclined to use more water at baseline. For example, if a treatment led a homeowner to water his or her lawn one fewer day per week, this would lead to a larger decrease in water use for homes that use more gallons each time they water their lawn. Therefore, we examine how the effects of the treatments differ based on baseline water-use intensity (i.e. a continuous measure of water use in the previous year; median-split for ease of visualization in Figure 3). We find a significant interaction between the Public Good treatment and prior household water use (coeff=-.20, 95\% CI[-.36, -.03], $t=-2.31, p=.021$ ); thus, Public Good messaging reduced water use (compared to control) to a greater extent for households that use more water at baseline. Conversely, there was no significant interaction between the Private Benefit treatment and prior household water use (coeff=-.01, 95\% CI[-.19, .17], $t=-.10, p=.917$ ). Further, comparing the two interaction terms shows that the interaction of prior household water use with the Public Good treatment is greater than with the Private Benefit treatment $(F(1,10141)=5.45, p=.020)$. We note that the low prior water use households are nearly twice as wealthy as the average US household (97\% greater estimated real-estate value; see SI Section 1), whereas the high prior water use households are more than three times as wealthy $(225 \%$ greater estimated real-estate value) than the average US household (note that real-estate value is the top contributor to household wealth; U.S. Census Bureau, 2015). Thus, our disaggregated analysis provides further support for our hypothesis that activating social motivations for reducing resource consumption is an effective strategy among the wealthy. 


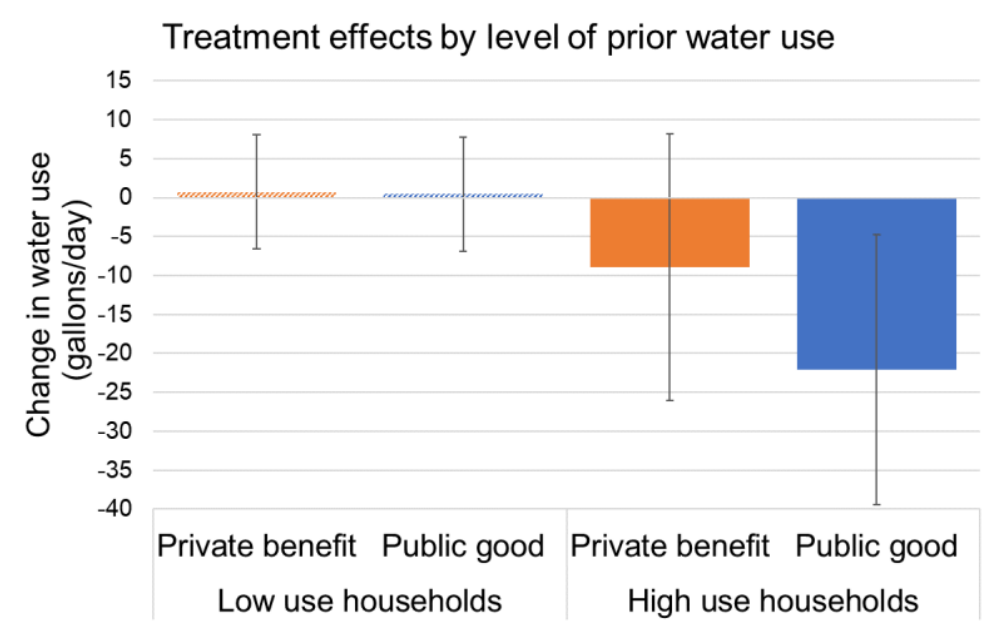

Figure 3. Public Good messaging reduces water use more than Private Benefit messaging for higher use households. Shown are average treatment effects on gallons per day relative to control among the Low prior use households (dashed) and High prior use households (solid), based on a median split of withinhousehold water use (in the same months as treatment during the previous year). Prior use is discretized for ease of visualization, though reported treatment effects calculated from regression models include continuous measure of prior use without controls. Error bars represent $95 \%$ confidence intervals.

\section{Experiment 2a}

In Experiment 2a, we aimed to provide a conceptual replication of our findings. We conducted a field experiment using Facebook's (FB) advertising platform to target wealthy users in Connecticut (by targeting users whose household income was in the top 10\%). We hypothesized that the Public Good ad would result in greater engagement compared to the Private Benefits ad (as measured by Click-through rates, a commonly used digital marketing metric).

\section{Methods}

For the purposes of our study, we created two advertising creatives - a "Public Good" ad and a "Private Benefits" ad. As in Experiment 1, the "Public Good" ad emphasized the environmental and communal benefits of conserving water and the "Private Benefits" ad emphasized the financial benefits of water conservation (see Figure 4a). ${ }^{2}$ We then targeted wealthy users located in the state of Connecticut by using income-based targeting (Facebook allows advertisers to target users based on the average household income of their zip code and we only targeted users whose income was in the top $10 \%$ within Connecticut). In addition to the incomebased targeting, the ads were restricted to users who were ages of 22 and above (as they were more likely to own houses and/or were more likely to be one of the decision-makers regarding water usage in the house). The ads were placed on users' Facebook pages as they browsed freely and we ran the two ads until our budget of $\$ 320$ was exhausted.

\footnotetext{
${ }^{2}$ Note that we circumvent recently identified issues with using FB ads in behavioral research (Eckles et al., 2018): we explore engagement with ads (rather than making any causal claims about how ads change behavior); and we asked FB to optimize only the number of impressions (instead of an option that optimizes showing the ads to people who are more likely to click on an ad).
} 
a)

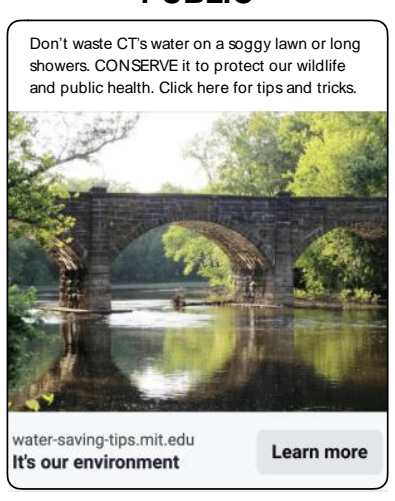

PRIVATE

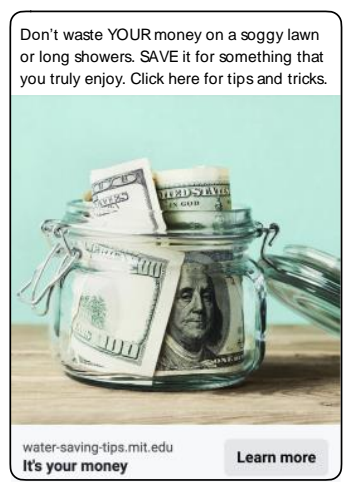

b)

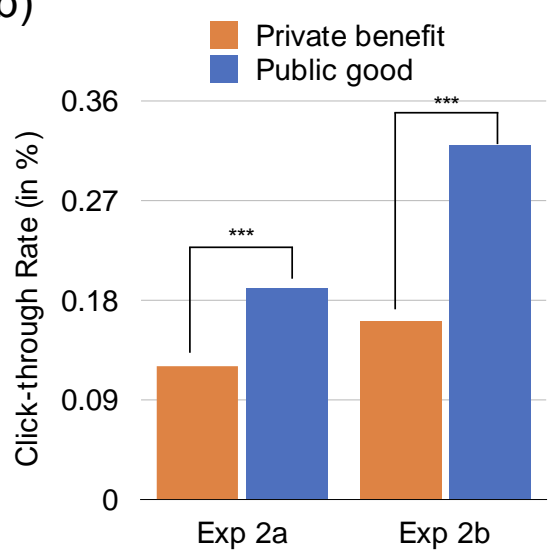

Figure 4. Users from high-income households engage significantly more with Public Goods ad compared to Private Benefit ad. (a) The "Public Good" and the "Private Benefit" ad used in Experiment 2a. We used the same ads in Experiment $2 b$ except that we changed the USPS state code in the "Public Good" ad. (b) Figure showing the click-through rate (CTR) for the "Private Benefit" ad and the "Public Good" ad. In both Experiment 2a and 2b, we find that the "Public Good" ad elicits significantly greater engagement (in terms of CTR).

\section{Results}

To test our hypothesis, we compared the effectiveness of the two ads as measured by clicks. Click-through rates (CTRs) are a commonly used digital marketing metric that quantifies the number of clicks relative to number of times the ad was shown. The "Public Good" ad was viewed 40,187 times (10,258 unique users) and was clicked 78 times. The "Private Benefits" ad was viewed 36,408 times (9,696 unique users) and was clicked 42 times. A two-sample Z-test of proportions revealed that the "Public Good" ad had significantly more clicks per view $(\mathrm{CTR}=.0019)$ than the "Private Benefits" ad $(\mathrm{CTR}=.0012, z=2.75, p=.006$; see Figure $4 \mathrm{~b})$. Further, the cost per link click (CPC) of the "Public Good" ad $(\mathrm{CPC}=\$ 5.82)$ was lower than that of the "Private Benefits" ad (CPC=\$7.01). Together, these results suggest that the "Public Good" ad resulted in greater engagement among the wealthy Facebook users in Connecticut and was also more efficient (in terms of cost per result).

\section{Experiment 2b}

In Experiment 2b, we conducted a pre-registered (https://osf.io/yts $2 \mathrm{q}$ ) replication of Experiment 2a in which we targeted wealthy users in the remaining five states of New England i.e., Maine, Massachusetts, New Hampshire, Rhode Island, and Vermont.

\section{Methods}

This study was similar to Experiment 2a, however, instead of Connecticut, we targeted wealthy users located in Maine, Massachusetts, New Hampshire, Rhode Island, and Vermont (using the same targeting as described above). In each state, we ran the two ads until our budget of \$200 was exhausted (we spent exactly \$100 for each ad in each state and thus spent \$1000 in total for the five states).

\section{Results}

As in Experiment 2a, we compared the effectiveness of the two ads as measured by clicks. The "Public Good" ad was viewed 69,698 times in total (20,800 unique users) and was clicked 
226 times. The "Private Benefits" ad was viewed 67,471 times in total (19,128 unique users) and was clicked 106 times. A two-sample Z-test of proportions revealed that the "Public good" ad received significantly more clicks per view $(C T R=.0032)$ than the "Private Benefits" ad $(\mathrm{CTR}=.0016, z=6.30, p<0.01$; see Figure $4 \mathrm{~b})$. Further, the cost per link click of the "Public Goods" ad $(\mathrm{CPC}=\$ 5.00)$ was lower than that of the "Private Benefits" ad $(\mathrm{CPC}=\$ 7.69)$. We also analyzed these results for each of the five states (see Table 1) and found that the "Public Good" ad generated significantly greater engagement in three states (MA, RI, and VT) and marginally higher engagement in two states (ME, NH). Together, results from Exp $2 \mathrm{a}$ and $2 \mathrm{~b}$ provide support to the findings in Experiment 1 and suggest that prosocial framing is an effective way to message the wealthy about sustainability.

\begin{tabular}{|c|c|c|c|c|c|c|c|}
\hline & \multicolumn{3}{|c}{ Public Good } & \multicolumn{3}{c|}{ Private Benefit } & \\
\hline State & Impressions & Clicks & CPC & Impressions & Clicks & CPC & $\begin{array}{c}\text { Z-test of } \\
\text { proportion }\end{array}$ \\
\hline ME & 13,011 & 41 & $\$ 4.76$ & 12,812 & 25 & $\$ 5.88$ & $z=1.91, p=.056$ \\
\hline MA & 23,659 & 54 & $\$ 3.45$ & 22,566 & 33 & $\$ 4.35$ & $z=2.03, p=.042$ \\
\hline NH & 10,811 & 32 & $\$ 11.11$ & 10,777 & 20 & $\$ 10.00$ & $z=1.65, p=.098$ \\
\hline RI & 11,461 & 44 & $\$ 4.17$ & 11,281 & 12 & $\$ 16.67$ & $z=4.23, p<.001$ \\
\hline VT & 10,756 & 55 & $\$ 5.88$ & 10,035 & 16 & $\$ 11.11$ & $z=4.35, p<.001$ \\
\hline Total & $\mathbf{6 9 , 6 9 8}$ & $\mathbf{2 2 6}$ & $\mathbf{\$ 5 . 0 0}$ & $\mathbf{6 7 , 4 7 1}$ & $\mathbf{1 0 6}$ & $\mathbf{\$ 7 . 6 9}$ & $z=\mathbf{6 . 3 0 , p < . 0 0 1}$ \\
\hline
\end{tabular}

Table 1. For each of the five states, this table shows the number of times the two ads were viewed (Impressions), the number of clicks they received (Clicks), and the cost per link click (CPC). Note that for each state, we spent exactly $\$ 100$ for each ad i.e., we spent a total of $\$ 500$ on Public Good ad and $\$ 500$ on Private Benefits ad.

\section{Discussion}

Here, we show that prosocial appeals to reduce household water use were effective in a large sample $(N=10,500)$ of relatively wealthy U.S. households (estimated real estate value $137 \%$ greater than the national average, see Figure 1a and SOM Section 1)-particularly among households with high baseline water use. We also conceptually replicated these results across two field experiments in the six states of New England (213,764 impressions, 59,882 unique users), demonstrating that prosocial framing results in greater engagement among the wealthy compared to self-interested framing.

Our results address a crucial gap in understanding how to promote sustainability: motivating the wealthy to reduce resource consumption. The wealthy disproportionately consume resources, while also being more likely to be insensitive to financial motivators, making their behavior harder to change using traditional economic incentives. Critically, however, economic incentives are not the only tool available for changing behavior. Here we show that appealing to prosocial motives can be effective. Our findings therefore contribute to theories of behavior change, as well as the understanding of psychologically-informed interventions for climate action in general and the challenges associated with the impact of SES on climate action in particular.

First, we note that our results are similar in magnitude (though directionally larger) compared to similar trials of messaging campaigns aimed at reducing household water use. Across 
four trials utilizing social norm messaging, significant reductions ranged from -2.51 to -9.69 gallons per day per household (Bhanot et al., 2018; Brent et al., 2015). Relevant to this prior work, our findings have broader implications for the literature on climate action interventions employing social norms (Nyborg et al., 2016). While interventions leveraging descriptive norms, i.e. beliefs about what others do, are consistently effective (e.g. for reducing home energy use; Allcott \& Rogers, 2014), such interventions require that a descriptive norm is established (i.e. that it is sufficiently common) in order to work. Alternative social norm interventions include evoking injunctive norms (e.g. Bhanot, 2021), i.e. beliefs about what others think people should do, as well as dynamic norms (e.g. Sparkman \& Walton, 2017), i.e. information about how descriptive or injunctive norms are changing over time. Yet, the efficacy of such interventions targeting wealthier populations may be limited because normative influence is less effective among higher SES individuals (Stephens et al., 2007), including in the domain of climate action (Eom et al., 2018). This effect may be exacerbated in highly individualistic cultures (such as the U.S.), in which wealthy individuals are more likely to exhibit reactance (Markus \& Kitayama, 1991), e.g. to climate action advocacy if they perceive that it limits their freedom. Alternative strategies for establishing new norms may therefore be required (Yoeli \& Rand, 2020), and our research demonstrates that prosocial framing may be an important tool for establishing new norms around climate action, particularly among the wealthy, where typical social norm intervention approaches may falter.

Broadly, our results are also consistent with previous work demonstrating the efficacy of prosocial framing in social dilemmas (e.g. Tenbrunsel \& Messick, 1999). Past research has also demonstrated spill-over effects of climate action interventions on other climate actions (e.g. Steinhorst et al., 2015), although we did not design our study to measure such effects (e.g. on home energy use). Given the urgency of climate change mitigation, and the disproportionate contribution of the wealthy to climate change and resource depletion, we suggest that future work should consider the viability of measuring (and encouraging) spillover effects when possible.

A major limitation to our study is the likely liberal skew in political beliefs of the population from which we drew our sample; for example, the percent split of Democrat/Republican votes in the 2020 presidential election was: $51.3 \% / 46.9 \%$ nationally; $59.3 \% / 39.2 \%$ in Connecticut; and $61.2 \% / 36.7 \%$ across New England (Federal Election Commission, 2021). Based on previous work examining the relationship of SES and climate action, we were more likely to find an effect of our prosocially-framed messages in this sample. First, climate change beliefs have been shown to vary by SES, whereby wealthier (and more educated) liberals are more likely to believe evidence on climate change whereas wealthier (and more educated) conservatives are less likely to believe evidence on climate change (Ballew et al., 2020). Second, support for climate change mitigation policy can be bolstered - even when it would be costly for individuals - when people feel that it is aligned with their values (Sparkman et al., 2021). Since wealthy liberals are more likely to believe evidence on climate change and also more likely to support personally costly climate change mitigation policy, we were more likely to find treatment effects in this sample than in a more nationally representative (i.e. more conservative) sample. Still, our work is consistent with previous findings demonstrating the efficacy of prosocial appeals (relative to self-interested ones) in motivating climate action (e.g. Bolderdijk et al., 2013), and provides the first evidence (to our knowledge) of such a relatively light-touch intervention to encourage climate action among the wealthy. Understanding how aspects of self-identitybeyond, but also including SES - relate to pro-environmental attitudes (Lou \& Li, 2021), and how this link can be translated to promote climate action remains a crucial direction for future research. 
In sum, our findings support the proposal that emphasizing public benefits and engaging social incentives can be an important tool for encouraging the wealthy to reduce their consumption, and engage in sustainable behaviors more generally. Considering the outsized impact of the wealthy on resource consumption and climate change, and the increasing urgency of climate change mitigation, such interventions are crucial and policy-relevant. We hope our work serves as an example of how appeals to the collective good can bring out good behavior in each of usparticularly for those who are least swayed by traditional economic incentives.

\section{Author Contributions}

All authors developed the study concept and contributed to the interventions and study design. Data collection and analysis were performed by G. T. Kraft-Todd, R. Dubey, and S. Bhanot. G. T. Kraft-Todd and R.Dubey performed the interpretation under the supervision of D. Rand. G. T. Kraft-Todd drafted the manuscript, and R. Dubey, E. Yoeli, S. Bhanot, and D. Rand provided critical revisions. All authors approved the final version of the manuscript for submission.

\section{Acknowledgements.}

Our thanks to Dana Haasz and the team at WaterSmart Software for making this work possible. We also thank our public utility partner in Connecticut. Thanks also to Tyler Soutendijk for excellent research assistance. 
***THIS WORKING PAPER HAS NOT YET BEEN PEER-REVIEWED***

\section{References}

Allcott, H., \& Rogers, T. (2014). The Short-Run and Long-Run Effects of Behavioral Interventions: Experimental Evidence from Energy Conservation. American Economic Review, 104(10), 3003-3037.

Ballew, M. T., Pearson, A. R., Goldberg, M. H., Rosenthal, S. A., \& Leiserowitz, A. (2020). Does socioeconomic status moderate the political divide on climate change? The roles of education, income, and individualism. Global Environmental Change, 60, 102024. https://doi.org/10.1016/j.gloenvcha.2019.102024

Bhanot, S. (2017). Rank and Response: A Field Experiment on Peer Information and Water Use Behavior. Journal of Economic Psychology, 62, 155-172.

Bhanot, S. (2021). Isolating the effect of injunctive norms on conservation behavior: New evidence from a field experiment in California. Organizational Behavior and Human Decision Processes, 163, 30-42. https://doi.org/10.1016/j.obhdp.2018.11.002

Bhanot, S., Kraft-Todd, G. T., Rand, D., \& Yoeli, E. (2018). Putting social rewards and identity salience to the test: Evidence from a field experiment with teachers in Philadelphia. Journal of Behavioral Public Administration, 1(1). https://doi.org/10.30636/jbpa.11.20

Bolderdijk, J. W., Steg, L., Geller, E. S., Lehman, P. K., \& Postmes, T. (2013). Comparing the effectiveness of monetary versus moral motives in environmental campaigning. Nature Climate Change, 3(4), 413-416. https://doi.org/10.1038/nclimate 1767

Brent, D. A., Cook, J. H., \& Olsen, S. (2015). Social Comparisons, Household Water Use, and Participation in Utility Conservation Programs: Evidence from Three Randomized Trials. Journal of the Association of Environmental and Resource Economists, 2(4), 597-627. https://doi.org/10.1086/683427

Brons, M., Pels, E., Nijkamp, P., \& Rietveld, P. (2002). Price elasticities of demand for passenger air travel: A metaanalysis. Journal of Air Transport Management, 8(3), 165-175. https://doi.org/10.1016/S09696997(01)00050-3

Chakravarty, S., Chikkatur, A., Coninck, H. de, Pacala, S., Socolow, R., \& Tavoni, M. (2009). Sharing global CO2 emission reductions among one billion high emitters. Proceedings of the National Academy of Sciences, 106(29), 11884-11888. https://doi.org/10.1073/pnas.0905232106

Dubois, D., Rucker, D. D., \& Galinsky, A. D. (2015). Social class, power, and selfishness: When and why upper and lower class individuals behave unethically. Journal of Personality and Social Psychology, 108(3), 436449. http://dx.doi.org/10.1037/pspi0000008

Dykema, J., Stevenson, J., Day, B., Sellers, S. L., \& Bonham, V. L. (2011). Effects of Incentives and Prenotification on Response Rates and Costs in a National Web Survey of Physicians. Evaluation \& the Health Professions, 34(4), 434-447. https://doi.org/10.1177/0163278711406113

Eckles, D., Gordon, B. R., \& Johnson, G. A. (2018). Field studies of psychologically targeted ads face threats to internal validity. Proceedings of the National Academy of Sciences, 115(23), E5254-E5255. https://doi.org/10.1073/pnas.1805363115

Engel, C., \& Rand, D. G. (2014). What does "clean" really mean? The implicit framing of decontextualized experiments. Economics Letters, 122(3), 386-389. https://doi.org/10.1016/j.econlet.2013.12.020

Eom, K., Kim, H. S., \& Sherman, D. K. (2018). Social class, control, and action: Socioeconomic status differences in antecedents of support for pro-environmental action. Journal of Experimental Social Psychology, 77, 60-75. https://doi.org/10.1016/j.jesp.2018.03.009

Evans, L., Maio, G. R., Corner, A., Hodgetts, C. J., Ahmed, S., \& Hahn, U. (2013). Self-interest and proenvironmental behaviour. Nature Climate Change, 3(2), 122-125. https://doi.org/10.1038/nclimate1662

Federal Election Commission. (2021). Official 2020 presidential general election results. https://www.fec.gov/resources/cms-content/documents/2020presgeresults.pdf

Grafton, R. Q., Ward, M. B., To, H., \& Kompas, T. (2011). Determinants of residential water consumption: Evidence and analysis from a 10-country household survey. Water Resources Research, 47(8).

Grant, A. M., \& Hofmann, D. A. (2011). It's Not All About Me: Motivating Hand Hygiene Among Health Care Professionals by Focusing on Patients. Psychological Science, 22(12), 1494-1499. https://doi.org/10.1177/0956797611419172

Harlan, S. L., Yabiku, S. T., Larsen, L., \& Brazel, A. J. (2009). Household Water Consumption in an Arid City: Affluence, Affordance, and Attitudes. Society \& Natural Resources, 22(8), 691-709. https://doi.org/10.1080/08941920802064679

IPCC. (2021). Climate Change 2021: The Physical Science Basis. Contribution of Working Group I to the Sixth Assessment Report of the Intergovernmental Panel on Climate Change (Masson-Delmotte, V., P. Zhai, A. Pirani, S., L. Connors, C. Péan, S. Berger, N. Caud, Y. Chen, L. Goldfarb, M. I. Gomis, M. Huang, K. 
Leitzell, E. Lonnoy, J. B., \& R. Matthews, T. K. Maycock, T. Waterfield, O. Yelekçi, R. Yu and B. Zhou, Eds.). Cambridge University Press. https://www.ipcc.ch/report/ar6/wg1/\#FullReport

Jordan, J., Yoeli, E., \& Rand, D. (2020). Don't get it or don't spread it: Comparing self-interested versus prosocial motivations for COVID-19 prevention behaviors. PsyArXiv. https://doi.org/10.31234/osf.io/yuq7x

Korndörfer, M., Egloff, B., \& Schmukle, S. C. (2015). A Large Scale Test of the Effect of Social Class on Prosocial Behavior. PLOS ONE, 10(7), e0133193. https://doi.org/10.1371/journal.pone.0133193

Liberman, V., Samuels, S. M., \& Ross, L. (2004). The Name of the Game: Predictive Power of Reputations versus Situational Labels in Determining Prisoner's Dilemma Game Moves. Personality and Social Psychology Bulletin, 30(9), 1175-1185. https://doi.org/10.1177/0146167204264004

List, J. A., Metcalfe, R. D., Price, M. K., \& Rundhammer, F. (2017). Harnessing Policy Complementarities to Conserve Energy: Evidence from a Natural Field Experiment. https://doi.org/10.3386/w23355

Lou, X., \& Li, L. M. W. (2021). The relationship between identity and environmental concern: A meta-analysis. Journal of Environmental Psychology, 76, 101653. https://doi.org/10.1016/j.jenvp.2021.101653

Markus, H. R., \& Kitayama, S. (1991). Culture and the self: Implications for cognition, emotion, and motivation. Psychological Review, 98(2), 224-253. http://dx.doi.org/10.1037/0033-295X.98.2.224

Norton, M. I., \& Ariely, D. (2011). Building a Better America-One Wealth Quintile at a Time. Perspectives on Psychological Science, 6(1), 9-12. https://doi.org/10.1177/1745691610393524

Nyborg, K., Anderies, J. M., Dannenberg, A., Lindahl, T., Schill, C., Schluter, M., Adger, W. N., Arrow, K. J., Barrett, S., Carpenter, S., Chapin, F. S., Crepin, A.-S., Daily, G., Ehrlich, P., Folke, C., Jager, W., Kautsky, N., Levin, S. A., Madsen, O. J., ... de Zeeuw, A. (2016). Social norms as solutions. Science, 354(6308), 42-43. https://doi.org/10.1126/science.aaf8317

Piff, P., Kraus, M., Côté, S., Cheng, B., \& Keltner, D. (2010). Having less, giving more: The influence of social class on prosocial behavior. Journal of Personality and Social Psychology, 99(5), 771-784. pdh. https://doi.org/10.1037/a0020092

Piff, P., Stancato, D., Cote, S., Mendoza-Denton, R., \& Keltner, D. (2012). Higher social class predicts increased unethical behavior. Proceedings of the National Academy of Sciences, 109, 4086-4091.

Reiss, P. C., \& White, M. W. (2005). Household Electricity Demand, Revisited. The Review of Economic Studies, 72(3), 853-883. https://doi.org/10.1111/0034-6527.00354

Schwartz, D., Bruine de Bruin, W., Fischhoff, B., \& Lave, L. (2015). Advertising energy saving programs: The potential environmental cost of emphasizing monetary savings. Journal of Experimental Psychology: Applied, 21(2), 158-166. http://dx.doi.org/10.1037/xap0000042

Sebri, M. (2014). A meta-analysis of residential water demand studies. Environment, Development and Sustainability, 16(3), 499-520. https://doi.org/10.1007/s10668-013-9490-9

Shorrocks, A., Davies, J., \& Lluberas, R. (2020). Global wealth report 2020. Credit Suisse Research Institute.

Sparkman, G., Attari, S. Z., \& Weber, E. U. (2021). Moderating spillover: Focusing on personal sustainable behavior rarely hinders and can boost climate policy support. Energy Research \& Social Science, 78, 102150. https://doi.org/10.1016/j.erss.2021.102150

Sparkman, G., Geiger, N., \& Weber, E. U. (2022). Americans experience a false social reality by underestimating popular climate policy support by nearly half. Nature Communications, 13(1), Article 1. https://doi.org/10.1038/s41467-022-32412-y

Sparkman, G., \& Walton, G. M. (2017). Dynamic Norms Promote Sustainable Behavior, Even if It Is Counternormative. Psychological Science, 28(11), 1663-1674. https://doi.org/10.1177/0956797617719950

Steinhorst, J., Klöckner, C. A., \& Matthies, E. (2015). Saving electricity - For the money or the environment? Risks of limiting pro-environmental spillover when using monetary framing. Journal of Environmental Psychology, 43, 125-135. https://doi.org/10.1016/j.jenvp.2015.05.012

Stephens, N. M., Markus, H. R., \& Townsend, S. S. M. (2007). Choice as an act of meaning: The case of social class. Journal of Personality and Social Psychology, 93(5), 814-830. http://dx.doi.org/10.1037/00223514.93.5.814

Tenbrunsel, A. E., \& Messick, D. M. (1999). Sanctioning systems, decision frames, and cooperation. Administrative Science Quarterly, 44(4), 684-707. https://doi.org/10.2307/2667052

U.S. Census Bureau. (2015). Housing QuickFacts. https://www.census.gov/quickfacts/table/HSG010215/00

U.S. Energy Information Administration. (2015). Annual Energy Outlook (No. AEO2015).

West, S. E. (2004). Distributional effects of alternative vehicle pollution control policies. Journal of Public Economics, 88(3), 735-757. https://doi.org/10.1016/S0047-2727(02)00186-X

Wiedmann, T., Lenzen, M., Keyßer, L. T., \& Steinberger, J. K. (2020). Scientists' warning on affluence. Nature Communications, 11(1), Article 1. https://doi.org/10.1038/s41467-020-16941-y 
Worthington, A. C., \& Hoffman, M. (2008). An Empirical Survey of Residential Water Demand Modelling. Journal of Economic Surveys, 22(5), 842-871. https://doi.org/10.1111/j.1467-6419.2008.00551.x

Yoeli, E., \& Rand, D. (2020). A checklist for prosocial messaging campaigns such as COVID-19 prevention appeals. PsyArXiv. https://doi.org/10.31234/osf.io/rg2x9 